be correct, because it tallies with results from 'variable-d' measurements, and the small values handled in Fig. I were designed for exact comparison, rather than for absolute measure.

For practical application in thermionic heating the prediction of capacity which will result from handpacking a given weight of cotton into a known volume of inter-electrode space must be rather approximate. The hairs are variously oriented and neither curve of Fig. 1 will apply. From simple geometrical considerations it is evident that the transverse field result will be closely applicable with tight compression, and an average of the two if the hairs were fluffily oriented in all directions. Neither condition would be met in testing-house practice. Rough trials indicate that it should suffice to take the transverse field value and raise it by 10 per cent.

The above results can only be considered as fair approximations, for the sources of error with cotton are various. The volume of dry cotton is calculated from the weight on the value accepted, of $1.55 \mathrm{sp} . \mathrm{gr}$. But we know that the cotton swells as it takes up moisture $e^{2}$; How and when does this appreciably affect our computation? One may even ask, What is cotton?

Another error had to be compromised, namely, the lag of cotton in attaining moisture equilibrium. Slater's work ${ }^{3}$ showed that three days should elapse before testing after any change of moisture content. We minimized this by re-circulating air through the perforations of the condenser, at ten litres a minute. on an Austen diaphragm pump. Even so, though successive results plot smoothly during a day's work there may be a shift during the night, the magnitude of which varies with the packing, with the zigzag of the air-flow paths, and so on. It is rarely large enough to require correction by a final plotting of the curve through these stabilized points ; thus, Fig. 2 is plotted from raw data.

A cognate source of error is the change of cotton temperature when gaining or losing water. With the condenser and a wash-bottle of water both nominally at room temperature, the cotton during recirculation may presently cease to take up any more water, or even lose water back to the bottle, as shown by a capacity-fall or by weighing. Changes in small steps mitigate this, but precision can only be got by threeday waits between changes.

There is, of course, no hysteresis loop in Fig. 2, because the actual weight of the cotton-water complex is plotted against the capacity, though the equilibrium lag ean sometimes simulate it.

Particular attention was directed to the known phase boundaries of the relation between cottonproperties and moisture content, shown by the studies of Slater and Goshawk to exist in regions corresponding roughly to 3,5 and 10 per cent moisture content. The present results are not good enough to provide a definite conclusion, but an anomaly in resistance was twice shown by longitudinal tests in the 3 per cent region, where Slater's Iongitudinal D.C. resistance curve is sharply bent; there is definite acceleration of the curves for both resistance and capacity in the 5 per cent region; the capacity curve is straight up to 3 per cent, as exemplified in Fig. 2. The 10 per cent region has only been roughly examined; a series condenser used to extend the range makes the resonance curve less blunt and more readable.

A point of interest in Fig. 2 is that the curve passes smoothly down through drying at $100^{\circ} \mathrm{C}$. to drying at $115^{\circ} \mathrm{C}$. More important is the fact that though the rise of capacity with moisture content accelerates, its rate of rise nowhere approaches the magnitude which free water with a $K$ of 81 actually produced in the apparatus used. Up to 11 per cent moisture we are certainly not dealing with free water, but the stage when it appears should be interesting to examine.

Some determinations on wood were made by packing the condenser used for Fig. 1 with a hundred small wood cubes, arranged with the grain running from plate to plate (longitudinal field) and again with grain parallel to the plates (transverse field). A ratio of $16 / 10$ in capacity was found. It would seem that the anisotropy is a property of secondary cellulose structures in general.

The encased and perforated condensers lent themselves to rough parallel determinations of the relative humidity of the air recirculating through them, using apparatus previously described ${ }^{4}$; also, of the obstruction to air-flow offered by the cotton as it swelled with water-intake, by putting an inclined differential alcohol manometer on the two sides of the casing. The results agreed with expectation, and a fuller investigation might include measurement of the cotton temperature by incorporating a thermojunction in the live plate. Capacity, resistance, humidity, permeability and temperature could all be measured together.

My thanks are due to my colleagues, H. A. Hancock, D. S. Gracie and F. Khalil for all facilities.

${ }^{1}$ Balls, W. L., "Studies of Quality in Cotton" (London: Macmillan, 1928), Figs. 3 3 .

${ }^{2}$ Goshawk, E. R., unpublished, summarized in W. L. Balls (ref. 1). s Slater, F. P., Proc. Roy. Soc., B, 96, 121 (1924). (Summary in W. L. Balls, ref. 1.)

- Balls, W. L., Nature, 152, 389 (1943).

\section{SHRINKAGE AND CRACKING OF CEMENTIVE MATERIALS}

THE symposium organised by the Roads and Building Materials Group of the Society of Chemical Indygtry and held at the Royal Institution on May 8 Tas 1 . Wirst result of a suggestion made by Prof. An. Bernal, chairman of the Scientific Advisory cesmomittee of the Ministry of Works, that there was ned for mog as assion of the fundamental problems associated fith lbuilding. The subject chosen, the shrinkage and cracking of cementive materials, is not only one of major importance to all building tech. nologists, but it also throws up many problems which, it is hoped, may engage the attention of the worker in pure science. The symposium was organised in collaboration with the Ministry of Works, and, in opening it, Sir Reginald Stradling, chief scientific adviser to the Ministry, pointed out that the problem of the dimensional stability of materials is a most important subject, and one which has engaged the attention of workers in this field over the last twenty years. Nevertheless, much still remains to be done, and he hoped that the contributions made to the symposium would lead to a clearer understanding of the nature of the problems.

Two of the papers, one by M. R. L'Hermite, director of the Laboratoires du Bâtiment et des Travaux Publics, Paris, and the other by Dr. F. M. Lea and Mr. C. R. Le日 of the Building Research Station at Watford, dealt with problems of conerete, the former discussing recent studies made in the author's labora. tory on the shrinkage of concrete, and the latter 
giving a general survey of the main facts relating to shrinkage and creep phenomena and of the theories of their causes.

It is well known that, even in the absence of applied loads, concrete is liable to undergo volume change. Apart from thermal effects and other minor causes, these volume changes are caused by alterations in the moisture content of the material, and restraint of them leads to the development of stress and, in the limit, to cracking. Thus, when concrete changes from a saturated to a completely dry condition, the contraction occurring is approximately the same as that which would be caleulated, on the usual simplifying assumptions, as arising from an applied compressive stress of the order of $800 \mathrm{lb}$. per sq in. Under complete restraint, therefore, the stresses which arise are of the same order as the normal permissible design compressive stress and greater than the ultimate tensile stress of the concrete.

Much can be done to reduce the risk of cracking; but nevertheless, cracking of concrete is of common occurrence and has come to be regarded as an annoying, and somewhat unpredictable, phenomenon. Rational design in concrete is affected by the fact that the stress/strain ratio under applied load is not constant, but varies with the time that the load has been applied. Thus, on application of a load, concrete exhibits an immediate elastic strain, and then a further progressive strain or creep which continues for years, and which may become several times greater than the original immediate strain. Creep will often act in such a way as to relieve the effect of shrinkage, and both are obviously of major importance in design. A typical value for the drying shrinkage of concrete is about 0.05 per cent, though this may vary considerably, according to the nature of the concrete and the conditions to which it is exposed. The shrinkage of concrete on first drying is in part irreversible ; on subsequent cycles of wetting and drying a somewhat lesser movement occurs, but this is substantially reversible. Most measurements of shrinkage have been done on unrestrained specimens, but it is the stresses set up by restrained shrinkage rather than the magnitude of the free shrinkage which are of prime importance in practice.

Shrinkage of concrete has been variously attributed to capillary condensation, surface adsorption, solid solution or hydration phenomena. In the first two, attention is primarily directed to the pore structure of the mass, while in the latter two, it is the nature of the binding agent which is regarded as the dominating factor. Elaborating the capillary condensation theory, M. L'Hermite referred to recent studies with the electron microscope made in the United States, from which it appears that hydrated cement consists essentially of a matrix of interlaced fibrous crystals, in which are embedded other crystals of a more massive plate-like shape. Cohesion of the cement is to be attributed to the presence of these fibrous crystals, but their very karge surface area must give rise to capillary and surface phenomena which, in M. L'Hermite's view, lie at the root of the dimensional changes of concrete with change in moisture content. Elaborating the capillary condensation theory, M. L'Hermite calculates the equivalent compressive stress induced in solids by water held in capillaries under tension and arrives at an expression relating shrinkage to the volume compressibility, relative humidity and combined water content of the concrete, which shows moderate agreement with the experimental results. As was pointed out, however, in other papers, there are numerous objections to capillary condensation as an explanation of volume change, and it is doubtful if it can at best be more than one of a number of factors concerned. M. L'Hermite also discussed the internal stresses set up in concrete by shrinkage, and in particular the stress in the reinforcement. From a consideration of the stresses in the concrete and the compression in the reinforcement, he is able to calculate the extent of cracking and the time at which it will occur.

Creep of concrete differs from plastic flow in metals in that it occurs down to the lowest stresses at which measurements are possible. For stresses within normal working ranges, creep for any one concrete is approximately proportional to the applied stress. The real distinction between shrinkage and creep in concrete is, however, not elear, for, in the case of specimens stored in air and undergoing creep tests, drying is usually occurring at the same time, and, with it, drying-shrinkage. The distinction between the two depends, therefore, on the assumption that they can be regarded as independent, and that creep can be measured as the increased deformation of a loaded specimen as compared with one which is not loaded but is maintained under otherwise similar conditions. Creep of concrete under water is not, of course, complicated by this shrinkage, though there is some slight expansion caused by further hydration of the cement. So far as all experimental evidence goes, creep is largely irrecoverable, but it has been argued that this is due to ageing effects in the concrete while under the test. Creep has been variously regarded as an irreversible phenomenon, as a delayed elastic phenomenon, and as such theoretically reversible, or as merely the consequence of nonuniform shrinkage. Much more data on the effect of the moisture content of concrete and of temperature on creep are vital to any theory.

In his paper on "The Swelling and Shrinkage of Porous Materials and the Role of Surface Forces in Datermining the Technical Strength of Artefact Materials", Dr. D. H. Bangham pointed out that the common observation that a liquid tends to form drops means that the idea of a liquid possessing surface energy is easy to grasp ; but it is not so easily realized that solids also have surface energy. Nevertheless, the surface tension of solids is many times greater than that of liquids. The reason why a powder does not coalesce into a solid mass is that the areas of contact between the grains are small, and the mutual pull of the particles is resisted by the rigidity of the material. The coalescence of solids thus depends partly on the magnitude of the surface forces and partly on the resistance to deformation. This, for example, explains why particles of wax with a low surface tension cohere together more strongly than particles of diamond with a high surface tension.

Meehan was the first to demonstrate in 1927 the swelling of charcoal when it absorbs gases and vapours. The detailed studies which have been made by Bangham and his collaborators have shown that the expansion is proportional to the surface-energy lowering which accompanies adsorption. This result is intelligible if it is remembered that the original size of the solid charcoal represents a compromise or balance between two opposing sets of forces: (1) the surface forces which, if left to themselves, would aggregate the material into a sphere of zero porosity ; and $(2)$ the elastic forces which impart rigidity to the material. The adsorption of the gas or vapour shifts the balance slightly against the surface forces, so that 
the block expands. Some experiments carried out in the laboratories of the British Coal Utilization Research Association have, in fact, shown that adsorption of vapour does cause some diminution of the area of contact between sub-microscopic particles. Thus, in experiments on the electrical conductivity of a rod of coke-like material, it was found that, when adsorption swelling took place, the resistance increased, indicating that the width of the inter-particle contacts had diminished. Different types of irreversible shrinkage, all well known in technical practice, were mentioned. The first, ageing, is most marked with a freshly aggregated mass of very fine particles or filaments. The slow prevailing of the surface over the elastic forces is probably due to molecular relaxations within the solid particles, which absorb the elastic energy and impart permanent set, with permanent adjustment of the particles to each other's shape at the area of contact. The shrinkage associated with drying may represent a continuation of this process, since the surface forces would be increased. The process of sintering is another illustration of the relative instability of the powdered state. Raising the temperature renders less effective the energy barriers which impart rigidity, and this appears to be the essence of the process.

Capillary condensation, in Dr. Bangham's view, appears to be subject to very serious limitations as an explanation of volume change of solids with changing content of liquid. The decrease of surface tension of a solid caused by saturation with the vapour of a liquid far exceeds the surface tension of the liquid itself. Thus, the surface energy of solids is of the order of thousands of ergs per sq. cm., the lowering of surface energy of solids by saturation of vapours is of the order of hundreds of ergs per sq. cm., while the surface energy of water, for example, is seventy-five ergs per sq. cm., and that of alcohols only twenty-two ergs per sq. cm.

Mr. H. H. Macey (British Refractories Research Association), in his paper on the "Cracking of Plastic Clay Articles during Drying", discussed many of the technical problems involved in manufacture. In the manufacture of any article from clay the ground raw material is mixed with sufficient water to render it capable of being moulded to the required shape, and, afterwards, it is dried to remove this water, and then fired. Problems of drying to avoid losses owing to shrinkage cracking are thus of much importance to the clay industry. A mixture of clay and water shows two distinct portions in the volume shrinkage/ moisture content curve. During the first stage, the change in volume is equal to the volume of water lost, but below a certain moisture content shrinkage for all practical purposes ceases. The order of movement with which Mr. Macey was concerned here is, of course, large compared with the dimensional changes undergone by rigid solids with change in moisture content that were discussed in the previous papers. In effect, the second stage referred to by Mr. Macey, in which volume change is very small, is the parallel to the behaviour of a rigid solid. The moisture content at which the first-stage shrinkage ceases varies considerably with the type of clay, and although it generally lies within the range of 8-13 per cent of water, it may be as high as 20 per cent. Under constant conditions of temperature and humidity, the rate of evaporation while shrinkage is taking place is constant, and very close to that of the free water surface, and it is only when the shrinkage ceases that the water surface retreats below that of the clay and evaporation is governed by diffusion through the pores and the reduced vapour pressure. Mellor explained the shrinkage behaviour of a clay by the supposition of continuous water films between the surface of the clay particles. During drying, the shrinkage of these films results in a change of volume equal to the volume of water lost, and this holds until the particles come into contact and shrinkage ceases. The thickness of the water films in a plastic clay appear from recent work to be of the order of, but probably less than, 1,000 A.

The last formal paper of the symposium was by Mr. F. R. Himsworth (Imperial Chemical Industries, Ltd.), on the setting and expansion of plasters, and thus dealt with a rather different topic. The expansion of plaster of Paris on setting has been utilized for a long time to give sharp castings, and this valuable property has been the subject of many investigations; nevertheless, the results obtained are still inconclusive. Calcium sulphate exists in three states of hydration, anhydrite, gypsum, and the lower hydrate, generally known as hemihydrate or plaster of Paris ; but the system is not so simple as it appeared. The hemihydrate seems not to be a definite hydrate but to behave like a zeolite, the limits of composition being $\mathrm{CaSO}_{4}$ and $3 \mathrm{CaSO}_{4} \cdot 2 \mathrm{H}_{2} \mathrm{O}$. The linear expansion of plaster of Paris on setting varies widely, being as high as 1 per cent in some cases and less than $0 \cdot 1$ per cent for the special low-expansion types. The actual volume change in the system in the reaction

$$
\mathrm{CaSO}_{4} \cdot \frac{2}{3} \mathrm{H}_{2} \mathrm{O}+{ }_{3}^{4} \mathrm{H}_{2} \mathrm{O}=\mathrm{CaSO}_{4} \cdot 2 \mathrm{H}_{2} \mathrm{O}
$$

involves a reduction of about 4 per cent. The expansion must, therefore, be explained in some way by the mode of crystal growth. Gypsum formed from the hydration of the plaster of Paris crystallizes in the monoclinic system, but its crystal habit varies greatly according to the solution from which it crystallizes. Accelerators of set in general tend to give small rodlike or needle crystals and, though they do not greatly increase the number of nuclei formed, they increase the rate of growth. Retarders have more marked effects, in general, reducing the number of nuclei formed and also the rate of growth. The effect on crystal shape is generally to decrease the elongation and increase the size. Immediately after plaster is mixed with water and placed in the mould, there is a contraction in volume which stops as soon as the plaster begins to set and which, with retarded plasters, has a maximum value of about 0.15 per cent by volume. It is followed by an expansion which is roughly parallel to the rate of hydration. This behaviour can, Mr. Himsworth suggested, be explained by assuming that before the plaster acquires rigidity the crystals are free to move without restraint, and the true reduction in volume corresponding to the hydration process occurs. As soon, however, as a rigid structure is formed, unidirectional growth takes place under conditions of restraint and causes the apparent expansion. It may be noted in this connexion that there are theoretical difficulties in the assumption that growth of a crystal in a not completely confined space from its saturated solution can exert a pressure, and more direct experimental proof of such a process is still required.

In a short contribution to the afternoon session, Prof. Bernal commented that the fibrillar material revealed by electron-microscope studies of set cement suggests an analogy with certain other fibrillar materials such as tobacco mosaic virus, and with the behaviour they show when the concentration of their 
solutions is changed. Developing this in a concluding address, Prof. E. K. Rideal observed that the fibrils would presumably behave as supermolecules and that the ratio of crystalline to amorphous regions, which is of much importance with polymers, would probably have a large influence on the properties of set cement. In the dehydration of zeolites, water can be removed without altering the external appearance, but holes may be left in the structure which would admit molecules of hydrocarbons. More information is needed about energy changes in such processes. Some alumino-silicates have a disk-like structure, and up to four layers of water molecules can be adsorbed between each disk. The system remains ordered if water is removed slowly, but on quick drying a disordered state may result. For an ordered system, the expansion on wetting is lateral for a water-rich system, and perpendicular for a water-poor system. The transportation of silt within a cement mass may also be of importance. Prof. Rideal referred in addition to work on diffusion gradients at crystal edges and the existence of mobile layers at crystal boundaries. It is possible that re-arrangement in a cement-water system may take place by osmosis, by transportation of silt, or by molecular movements.

\section{F. M. L.}

\section{ANTHROPOLOGY ON THE CONTINENT OF EUROPE IN WAR-TIME}

\begin{abstract}
A $\mathrm{S}$ has already been reported in Nature of May 18, A p. 665, the Permanent Council of the Intermational Congress of Anthropological and Ethnological Sciences visited England during April at the invitation of the roye Anthropological Institute, and a most succossffit 1 dfing was organised at Oxford by Sir Johrovyres gne of the joint secretaries of the Congtss, to maks hrrangements for the next full meeting and to adegte the work of the standing committees. The Roy Anthropological Institute took advantage of this gathering to invite the delegates to read short papers at informal meetings of the Institute in London, on the days immediately preceding and following the Oxford meetings, as a means of making better known in Britain and among the delegates themselves the progress made in anthropological science in their several countries since the outbreak of war brought international contacts to a stop. Eleven of the delegates accepted this invitation, and in addition two of the delegates delivered during their visits the Huxley Memorial Lectures for 1941 and 1945.
\end{abstract}

Mention should first be made of a full and illustrated account, given by Miss Johanna Felhoen Kraal (one of the Netherlands delegates) at an ordinary meeting on April 2, of the work of the Ethnographical Section of the Netherlands Institute for the Indies at Amsterdam, and particularly of the development of its policy in recent years under the late Prof. B. J. O. Schrieke, whose death in 1945 was so grievous a loss to Holland, to the East Indies and to anthropological science.

At the first of the special meetings, held on April 11, Prof. J. M. de Barandiaràn, who attended as a delegate of France, gave an illuminating account of Basque studies during the past ten years, mainly under the auspices of the Basque Research Institute, founded in 1921, which publishes the Anuario de Etnologia and the monthly Eusko-Folklore. The outbreak of the Spanish Civil War interrupted a number of important excavations at prehistoric sites in Spain which had already thrown much light on the origins of the Basque type so far back as the upper Palæolithic. Since 1937, the Institute's work had been confined to the French side of the frontier, and was on a reduced scale, though Prof. Barandiaràn had himself made some important discoveries suggesting a correlation between the distribution of ancient dolmens and cromlechs and the nomadism still practised in the same areas. Ethnographical work included studies of current folk-lore which seemed to have prehistoric parallels.

Prof. Edouard de Jonghe (Brussels) gave a very full and authoritative account of war-time progress in anthropological knowledge of the Belgian Congo. Most of the Belgian universities, museums, learned societies and scientific publications carried on through. out the German occupation, generally on a reduced scale, and resisted German influence with success : there were practically no cases of 'collaboration' among anthropologists. Prof. de Jonghe himself was deported to Germany just before the arrival of the Allies in Belgium in 1944. The four years isolation of the metropolis from its colony naturally concentrated the energies of research workers in Belgium upon the working up of material already collected. In the Congo, on the other hand, the War saw a great expansion of anthropological research, especially in the applied field. Prof. de Jonghe's detailed account of work published during the War included, under the head of prehistory, works by Lobar and de Jonghe (in collaboration), Bertrand, Van der Kerken, Bequaert (on the prehistoric collections of the Tervueren Museum), Cabus, Van Moorsel and Mortelmans.

On the physical side, interesting and important work was done on the practical problems of health and demography; but in the special case of the pygmies much fundamental research was also carried out-by Father Schebesta, with his associates Jadin and Gusinde, on the Bambuti pygmies (including blood-group studies); by Jullien, on the blood-groups of the Efe pygmies; by Father Schumacher, in a monumental work to appear shortly, on the Lake Kivu pygmies; and by Twisselmans on the pygmies of West Africa, especially the French Congo. In the linguistic field, a vocabulary of Alur was compiled by Father Van Neste, and a grammar of Chiluba by Father Willems. The use of Chiluba as the national tongue of the whole Belgian Congo had long been advocated by Prof. de Jonghe, and an important session of the Institut Royal Colonial Belge was devoted to discussion of this problem in 1944. A preliminary essay in the application of linguistic geography to the Bantu languages was made by Father de Boeck.

Among general ethnological works was De Cleene's excellent "Introduction à l'Ethnographie du Congo" (written from a rather functional point of view), and important monographs were produced on the Mongo, Basongo and Bakongo by Van der Kerken, de Beaucorps and Mertens. News was also given of the Institute's great investigation of the forms of slavery in the Congo. Juridical ethnology made great strides in the Congo during the War under the influence of Sohier, as had the systematic study of Congo art in Belgium under that of Prof. F. M. Olbrechts. After a short reference to recent studies by Van Reeth, Smets and others in the religions of the Congo and Ruanda, Prof. de Jonghe concluded with an interest- 